\title{
The practice of everyday life provides supporters and inviters of morally responsible agency
}

\author{
doi:10.1017/S0140525X17000851, e64 \\ Jörg Zinken ${ }^{\mathrm{a}}$ and Vasudevi Reddy \\ aInstitut für Deutsche Sprache (IDS), 68161 Mannheim, Germany; \\ ${ }^{b}$ Department of Psychology, University of Portsmouth, Portsmouth, United \\ Kingdom PO1 2DY. \\ zinken@ids-mannheim.de vasu.reddy@port.ac.uk \\ http://www1.ids-mannheim.de/prag/personal/zinken.html?L=1 \\ http://www.port.ac.uk/department-of-psychology/research/situated- \\ action-and-communication/
}

Abstract: Drawing on research from conversation analysis and developmental psychology, we point to the existence of "supporters" of morally responsible agency in everyday interaction: causes of our behavior that we are often unaware of, but that would make goodenough reasons for our actions, were we made aware of them.

Doris is troubled by "defeaters": causes of our behavior that we are not aware of and, to make things worse, that we would not think of as good reasons for our behavior were we made aware of them. Research in experimental social psychology claims to have identified many such defeaters. To cite one of Doris's examples, some people seem to vote for the guy at the top of the ballot, although they would probably not claim that "because he was top of the ballot" was the reason for their choice, or that it would make a good reason for anyone's choice. But if our decisions can be swayed in such irrational ways, the worry follows, how can we think of ourselves as responsible agents?

To soften the blow dealt to our agency by such potential "defeaters" and to support the overall thrust of Doris's work, we want to draw attention to research on everyday social life. Some of that research points to the existence of what we might call "supporters": causes of our behavior that we are often unaware of, but that would make good-enough reasons for our actions, were we made aware of them. Work in Conversation Analysis, which examines the normative order of our mundane social interactions, has identified many such supporters (e.g., Stivers et al. 2011; Zinken 2016).

Consider the ways a person might address a request for some action to another. Requests for small-scale acts of cooperation are ubiquitous in everyday life, and they provide a central arena for morally accountable agency. In languages around the world, we find complex systems of practices for making requests (Floyd et al. 2014). But how do I come to the decision to use an interrogative in one situation (Can you pass me a plate?) and an imperative in another (Pass me a plate)? As it turns out, we make these little decisions in highly systematic ways: Imperative requests - the predominant format for requesting little acts of cooperation across languages-build on the other's availability for the job, whereas interrogative requests take into account the fact that the other is occupied with something unrelated. In other words, a cause for choosing an interrogative over an imperative request is the relative lack of continuity of the requested action with what the other is already doing (e.g., Rossi 2012; Wootton 1997).

People seem to care about these contextual cues a lot. If your partner is standing in just the right spot to pass you the plate you want, you might begin to address him with an imperative. But if he begins to walk to the fridge right as you start talking, you might break off and restart your request in an interrogative format (data discussed in Zinken 2016). But when we asked videotaped participants about their choices in such everyday interactions, they either spoke broadly about matters of politeness, or suggested that their choice of request form was quite arbitrary. It seems then, and maybe unsurprisingly so, that we are not always aware of the subtle contextual cues that sway our decisions in our everyday interactions with others. But if we were made aware of them, would there be cause for embarrassment? I would say not: My more or less subliminal awareness of the fact that my partner's moving to 
the fridge constitutes an engagement that is in conflict with passing me a plate has moved me to express the value of respecting another person's autonomy. Two seconds earlier, my sensitivity to my partner's availability for cooperation had moved me to express another important value: our need to express closeness to others (Brown \& Levinson 1987). In sum, the contextual cues that regularly sway our decisions in designing interactional moves can indeed make good reasons for occasions when we are asked to rationalize what we did (see Doris 2015b, pp. 141-43). They are supporters rather than defeaters of our morally responsible agency.

Surely we do have our irrational moments. But maybe the extant research in social psychology over-advertises these a bit. Research on everyday adult interaction instead finds "supporters" of moral agency to be ubiquitous in our social lives. And from the earliest months of infancy, we are drawn into action by "inviters" of action and response, without which development would be impossibly difficult. Infants begin from 6 or 7 months of age to understand and comply with adult directives. However, rather than being enabled by a newly developed grasp of others' intentions, infants come to this gradually. The adults around set up contexts of repeated and routinized invitations to act, to attend, to show off their skills to visitors, and to join in easy cultural rituals (Reddy et al. 2013). Infants are drawn into participating in these engagements, and without direct focus on it, begin to grasp the very structures of moral participation in social life.

These inviters and supporters seem to fit well into the theory of the social genesis and development of morally responsible agency that Doris has argued for. Their recognition might further reduce the appeal of skepticism about responsibility and agency. 